\title{
Ser profissional de saúde em uma unidade neonatal de alto e médio risco: o visível e o invisível'
}

\author{
Being a neonatal high and medium risk level unit professional: \\ the visible and the invisible aspects
}

\author{
Claudia Egypto MACHADO² \\ Maria Salete Bessa JORGE ${ }^{3}$
}

\begin{abstract}
Resumo
Este estudo tem como objeto as vivências do profissional de saúde que trabalha em uma unidade neonatal de alto e médio risco. Utilizou-se como referencial teórico a fenomenologia hermenêutica de Martin Heidegger com o objetivo de compreender as vivências dos profissionais e as repercussões dessas vivências para sua saúde mental. Foram realizadas entrevistas fenomenológicas com os profissionais da unidade, chegando-se à compreensão, a partir da análise das unidades de significado encontradas, de que o sentido do ser-profissional-de-saúde nessa unidade transita entre o ôntico e o ontológico, na medida em que o profissional ora se protege no modo impessoal, ora se coloca no modo existencial ontológico de ser. Espera-se que a pesquisa possa contribuir para o enriquecimento e a humanização da relação profissional-paciente.
\end{abstract}

Palavras-chave: saúde mental; serviços de saúde mental; profissional de saúde; fenomenologia.

\begin{abstract}
The object of the present study is the experiences a professional who works at the high and medium risk level of neonatal unit is exposed. The Hermeneutic Phenomenology of Martin Heidegger was the theoretical referential in order to focus the professionals' experience and its effect on their mental health. The data collection method used was the Phenomenological interviews with the professionals from the high and medium risk level of neonatal units. According to the data analysis, it's possible to conclude that the meaning of being a professional from these units is between the ontic and the ontological, as these professionals work sometimes protecting themselves in an impersonal way, and sometimes putting themselves in existential-ontological place. There is a expectation this study contributes to the professional-patient relationship development and humanization.
\end{abstract}

Key words: mental health; mental health services; professional of health; phenomenological research.

O interesse pelas vivências de profissionais de saúde em unidades neonatais de alto e médio risco surge a partir da constatação, através da prática profissional e da pesquisa de literatura, do desconhecimento científico sobre essa realidade. Apesar do esforço empenhado no sentido de alcançar a

$\boldsymbol{\nabla} \mathbf{\nabla} \boldsymbol{\nabla}$

1 Artigo elaborado a partir da dissertação intitulada: "Ser profissional de saúde em uma unidade neonatal de alto risco: o visível e o invisível", Universidade Estadual do Ceará, 2004. Financiada pela Fundação Cearense de Apoio ao Desenvolvimento Ciêntífico e Tecnológico (FUNCAMP).

2 Curso de Psicologia, Centro de Ciências Humanas, Universidade de Fortaleza. Av. Washington Soares, 1321, Edson Qurioz, 80811-905, Fortaleza, Ceará, Brasil. Correspondência para/Correspondence to: C.E. MACHADO.E-mail: <cem@unifor.br>.

3 Curso de Mestrado Acadêmico em Saúde Pública, Centro de Ciências da Saúde, Universidade Estadual do Ceará. Fortaleza, Ceará, Brasil. E-mail: <massabejo@uece.br>. 
humanização da relação profissional de saúde-paciente, percebe-se que apenas um pólo dessa relação tem sido abordado de forma sistemática.

A sociedade atual está constantemente sensibilizada pela dor dos familiares e principalmente das mães de bebês internados nessas unidades, fato que se reflete inclusive no número de pesquisas sobre as vivências de mães de bebês em unidades neonatais (Morsch, 1990; Ribeiro, 1991; Lamy, 1995; Brito, 2002; Moreno, 2002). São trabalhos de uma riqueza enorme, que descrevem com profundidade as vivências, os sentimentos e as experiências dessas mães durante o período em que seus filhos estiveram internados em unidades neonatais. Entretanto, pouco dizem sobre as vivências e a realidade dos profissionais de saúde que ali trabalham. Nas poucas vezes em que são feitas referências à perspectiva dos profissionais, como as realizadas por Brito (2002), elas trazem implícita uma determinada expectativa ou exigência quanto à forma como esses profissionais devem se comportar no trato com os recém-nascidos (RN). Moreno (2002) também define uma expectativa de como o profissional de saúde deve agir em seu trabalho na unidade de terapia intensiva neonatal (UTIN), principalmente no que se refere à postura a ser adotada com as mães de bebês internados. Evidentemente que todas essas colocações em relação à postura do profissional de saúde que trabalha em UTIN são extremamente pertinentes para que haja qualidade no atendimento prestado. Entretanto, torna-se importante conhecer também as necessidades desses profissionais no âmbito do seu ambiente de trabalho.

Observando o dia-a-dia desses profissionais nesse tipo de unidade, os momentos de intensa pressão, o lidar com a vida e a morte tão de perto e, principalmente, com seres completamente frágeis e indefesos, inúmeros questionamentos sobre suas vivências começam a ser construídos. Como será que eles se sentem trabalhando nessa unidade neonatal? Que sentimentos vivenciam sabendo que lidam com seres que dependem totalmente de seus cuidados para permanecerem vivos? Que tipos de mecanismos de defesa constroem para lidar com a dor, o desespero e o medo com que convivem na relação com os familiares? Como dosam a enorme quantidade de tecnologia e as limitações decorrentes do fato de serem seres finitos? Como lidam com o "fracasso" profissional ao se depararem com a morte de um bebê?

Os profissionais de saúde inseridos em um ambiente tão característico como o das unidades neonatais de alto risco passam por uma série de experiências que precisam ser conhecidas caso se deseje realmente compreender a realidade vivida por esses profissionais no seu campo de trabalho. Torna-se importante relembrar que o ambiente hospitalar é marcado por sujeitos diversos: pacientes, familiares e profissionais.

Como exposto, a literatura mostra uma série de pesquisas sobre as vivências de recém-nascidos e seus familiares em unidades de terapia intensiva neonatal. Da mesma forma, os estudos sobre o trabalho em ambiente hospitalar estão se multiplicando devido à constatação de diversos autores da importância de compreender as repercussões desse tipo de trabalho para os profissionais. Assim, torna-se de fundamental importância a realização de pesquisas que procurem compreender o profissional inserido nesse contexto específico de trabalho: a unidade de terapia intensiva neonatal.

A partir do exposto, este estudo tem como objetivo compreender as vivências dos profissionais de saúde que trabalham em uma unidade neonatal de alto e médio risco e as repercussões dessas vivências para a saúde mental dos mesmos.

Este estudo se fundamenta nos pressupostos fenomenológicos heideggerianos, a partir da obra "Ser e tempo", na busca da compreensão do ser-profissional-de-saúde inserido na realidade da unidade neonatal.

\section{Fenomenologia hermenêutica}

Martin Heidegger, apontado como um dos maiores pensadores do século XX, é o autor da obra "Ser e tempo" (Sein und zeit), considerada, segundo Silva, Gurgel, Carvalho e Moreira (2001), uma das quatro maiores obras de toda a história da humanidade. Essa obra foi escrita em 1927, época em que aflorava o movimento do existencialismo na Europa pós-guerra, que vivia um momento de intensa retomada dos questionamentos sobre a existência humana pelo pensamento filosófico. 
Na busca de apreensão do ser, Heidegger funda a ontologia fundamental que procura as origens genuínas que possibilitam a tudo se manifestar e se apresentar (Spanoudis, 1981). Para Heidegger (2002), somente a ontologia fundamental pode se colocar diante do problema cardeal: a questão sobre o sentido do ser em geral. Esse filósofo desenvolve, assim, uma analítica existencial do homem, mostrando os modos de ser do humano e chegando ao único ente que poderia captar o sentido do ser e da existência: a presença, o Dasein, o ser-aí.

A pre-sença é um ente privilegiado, pois é o único ser que se interroga e, por isso, o único dotado da capacidade de perguntar e responder às perguntas. A ontologia fundamental " possui como tema a pre-sença, isto é, o ente dotado de um privilégio ôntico-ontológico" (Heidegger, 2002, p.68). Para Heidegger (2002), o ôntico refere-se a tudo que é percebido, entendido e conhecido de imediato. $\mathrm{O}$ autor refere-se a essa idéia como o que é existenciário. O ontológico, por outro lado, refere-se às características fundamentais que possibilitam as várias maneiras de algo se tornar manifesto, realizado. É o mundo das essências universais.

Nesse sentido, Heidegger $(2001$; 2002) enumera uma série de características ontológicas da existência do homem, as quais chama de existenciais. Uma das características ontológicas mais importantes da pre-sença é a sua constituição enquanto ser-no-mundo (in-der-Welt-sein), ou seja, o traço fundamental da sua existência é o fato de ser-no-mundo-com-os-outros-e-com-as-coisas. O homem, conforme Moreira, Barreto, Machado e Andrade (1999), não é um espectador passivo do mundo, pelo contrário, o homem está lançado no mundo e com ele interage, não estando preso a nenhuma situação, mas sempre aberto para se tornar algo novo. Essa possibilidade de se tornar algo novo, Heidegger (2002) chama de poderser.

Para Heidegger (2001) a pre-sença constrói o seu ser a partir da temporalidade. A temporalidade é a antecipação temporal do poder-ser. A pre-sença se temporaliza em porvir, atualidade e vigor de ter sido, compreendidos enquanto os ekstases da temporalidade. Na cotidianidade esses conceitos equivalem aos de futuro, presente e passado. Entretanto, para o filósofo, é necessário aprofundar a experiência ôntica e vulgar de tempo e isso só é possível a partir dos conceitos existenciais da temporalidade.

Para Heidegger (2002), existir é exercer os modos de temporalização. O ser, nessa temporalidade e na relação com os outros seres, pode ter uma coexistência autêntica ou inautêntica. A vida inautêntica, segundo Barguil e Leite (1997), acontece com quem se deixa levar pelos valores correntes e dominantes da sociedade, acreditando que tudo já está decidido na vida de cada dia. Moreira et al. (2002) define a existência inautêntica como aquela em que o ser compreende o mundo em conformidade com a opinião comum, vivendo uma vida anônima e aceitando a tradição passivamente, sem contestá-la.

Esse tipo de existência priva o homem da capacidade de alcançar uma verdadeira abertura em direção às coisas e uma verdadeira compreensão do ser. Heidegger (2002) chama esse modo de ser da pre-sença na cotidianidade de impessoal. Nesse modo, a pre-sença está sob a tutela dos outros. "Todo mundo é outro e ninguém é si próprio. O impessoal, que responde à pergunta quem da pre-sença cotidiana, é ninguém, a quem a pre-sença já se entregou na convivência de um com outro" (Heidegger, 2002, p.181).

O impessoal se expressa na cotidianidade através dos modos de ser: espaçamento, medianidade e nivelamento, que constituem a publicidade. É a publicidade que rege toda e qualquer interpretação da pre-sença e do mundo, tendo razão em tudo. Dessa forma, ela obscurece tudo, tomando o que se encobre por conhecido e acessível a todos.

O modo impessoal se manifesta na cotidianidade, pelo discurso, através de alguns modos: o falatório, no qual as coisas são aceitas como se apresentam na fala do senso comum, no que se diz; a curiosidade, que se caracteriza por uma busca incessante por novidades e pelo desejo de saber sobre o aparente sem interpretação ou compreensão; e a ambigüidade, em que tudo parece ter sido bem compreendido e captado mas que na verdade não foi ou não parece ter sido, quando na verdade foi. Nesse tipo de existência, o ser de-cai no mundo do se, da oscilação, gerando perda e alienação (Silva et al., 2001). 
Tem uma vida autêntica, para Barguil e Leite (1997), quem assume a vida como propriedade de si, construindo-a conforme um plano pessoal, a partir das possibilidades vislumbradas pelo ser. No campo do autêntico a existência se comporta realmente como ser-com, parte da estrutura ontológica do ser. Para Heidegger (2002) as estruturas ontológicas mais originárias da pre-sença são o ser-com e a co-pre-sença. "Não se dá um ser ou modo de ser isolado. Todo ser é sempre ser-com, mesmo na solidão e isolamento, a pre-sença é sempre co-pre-sença (Mitdasein), o mundo é sempre mundo compartilhado (Mitwelt), o viver é sempre con-vivência (Miteinandersein)" (p.319).

De acordo com Heidegger (2002), diante da inautenticidade, a consciência apela à pre-sença para que suas possibilidades de ser sejam aceitas. Esse apelo é o clamor da consciência, uma tentativa de recuperar o homem para o plano ontológico, um grito da angústia que chama a si a pre-sença e a leva ao poder ser autêntico. A disposição para o poder-ser é ontológica e se dá pelo humor, que revela como alguém está e se torna. A disposição se manifesta através de modos de ser: temor (fechamento inautêntico) ou angústia (abertura autêntica).

Segundo Heidegger (2002), o fenômeno do temor abarca tanto o temível (o que se teme) quanto o pelo que se teme e o próprio temer. O temível é sempre um ente que vem ao encontro dentro do mundo, possuindo, portanto, o caráter de ameaça, a partir do modo conjuntural de dano. O danoso não se acha ainda numa proximidade dominável, mas se aproxima. A ameaça constitui-se justamente pela aproximação na proximidade, podendo ou não chegar. A pre-sença possui ainda o modo da disposição de temer por, ou seja, ter medo em lugar de outro. Esse modo não retira o outro do temor, mas constitui-se muitas vezes justamente em ocasiões em que o outro não teme e audaciosamente enfrenta o que o ameaça.

A angústia é o sentimento fundamental do ser humano como ser-no-mundo; ela exprime o sentimento mais profundo, que é princípio e origem de todos os outros mas que se mantém normalmente velado ou latente. A angústia leva o ser a usar a sua liberdade para viver de forma autêntica ou inautêntica. A pre-sença angustia-se com o mundo pelo fato de supor uma ameaça que, no entanto, não é encontrada em parte alguma.
Nesse sentido, percebe-se que a angústia está ligada a uma outra característica existencial: a morte. Para Silva et al. (2002) essa característica é a unidade da totalidade do ser. É a última e, ao mesmo tempo, a sua possibilidade mais própria, pois é a única da qual o homem não pode fugir. Ao contrário do que se pensa, Heidegger (2001) explica que o homem encontra o próprio eu-autêntico quando compreende que a sua essência é de um ser-para-o-fim, pois a morte o liberta das banalidades mundanas e o faz enfrentar o cotidiano com coragem e resolução.

Torna-se importante colocar ainda uma última característica existencial da pre-sença: a cura, que é manifestada concretamente através do cuidado. Para Heidegger (2002) a cura é o modo-de-ser essencial do humano, sendo assim um fenômeno ontológico-existencial básico que possibilita a existência humana enquanto tal. A cura encontra-se no mundo sob duas formas de ser: a ocupação e a pre-ocupação. A ocupação refere-se à relação da presença com os seres simplesmente dados, ou seja, refere-se aos cuidados com as coisas do mundo. A pre-ocupação, por outro lado, está ligada ao cuidado com o outro, com o ser existente. A pre-ocupação oscila entre duas possibilidades extremas: o substituir e o antepor. Na substituição a pre-sença retira o cuidado do outro e tenta ocupar o seu lugar, assumindo o que deveria ser realizado por ele. No modo de antepor, por outro lado, a pre-ocupação antepõe o outro em sua possibilidade existenciária de ser, não para Ihe retirar o cuidado e sim para devolvê-lo. Nesse processo a pre-sença ajuda o outro a se tornar transparente em si mesmo e livre para a cura.

A essência do método fenomenológico de Heidegger repousa na compreensão e na interpretação das experiências vividas. A hermenêutica torna-se, portanto, um conceito fundamental na ontologia e constitui a base da investigação transcendental de Martin Heidegger (Moreira et al., 1999).

\section{Método}

Trata-se de um estudo de natureza qualitativa em virtude da necessidade de adentrar o rico e significativo mundo da subjetividade. A pesquisa 
qualitativa, de acordo com Martins e Bicudo (1994), busca uma compreensão particular daquilo que se está estudando, não se preocupa com generalizações, princípios e leis. O foco da atenção está centrado no específico, no peculiar, no individual, almejando sempre a compreensão e não a explicação do fenômeno estudado.

Dentre as várias opções que a pesquisa qualitativa dispõe, optou-se por utilizar a fenomenologia, uma vez que, de acordo com Forghieri (2001), o método fenomenológico é considerado o recurso apropriado para a pesquisa de vivências, pois procura captar o sentido ou o significado da vivência para a pessoa em determinadas situações por ela experienciadas em seu existir cotidiano. Dentro da fenomenologia, buscou-se mais especificamente a fenomenologia hermenêutica, baseada nos pressupostos de Martin Heidegger, que se volta inteiramente para a busca do sentido do ser, mais especificamente do ser humano.

A pesquisa foi desenvolvida em um hospital filantrópico da cidade de Fortaleza, CE, considerado um hospital geral que atende pacientes do Sistema Único de Saúde, (SUS), de convênios diversos e particulares. O hospital dispõe de 137 leitos, sendo divididos nas seguintes modalidades: clínica médica, clínica cirúrgica, obstetrícia, unidade de terapia intensiva (UTI) e unidade neonatal de alto e médio risco.

O hospital conta com uma equipe de profissionais das seguintes áreas: médicos (em diversas especialidades), enfermeiros, fisioterapeutas, nutricionistas, psicóloga, farmacêutica e, ainda, diversos profissionais da área técnica, tais como: administradores, técnicos administrativos, auxiliares de serviços gerais, motoristas, costureiras, vigias etc. O hospital dispõe ainda de serviços laboratoriais e de imagem, pronto-atendimento e quimioterapia.

O serviço de neonatologia é composto de duas unidades: o alojamento conjunto e a unidade neonatal de alto e médio risco. Ambas oferecem cobertura ao centro obstétrico do hospital. A unidade neonatal de alto e médio risco dispõe de treze leitos, sendo três destinados a alto risco e dez a médio risco. Nessa unidade trabalham 23 profissionais específicos da área de saúde: seis médicos, duas enfermeiras, onze auxiliares de enfermagem, três fisioterapeutas e uma psicóloga, além da equipe de limpeza e de laboratório.

Participaram da pesquisa os profissionais de saúde que fazem parte da equipe da unidade neonatal de alto e médio risco: médicos, enfermeiras, fisioterapeutas e auxiliares de enfermagem. $O$ quantitativo dos sujeitos foi determinado durante o processo de coleta (no campo de estudo empírico) e análise, tomando como critério a repetição dos discursos sobre o recorte do tema em estudo - processo de saturação teórica. A escolha desse critério segue a metodologia da pesquisa fenomenológica, uma vez que para ela o quantitativo não está relacionado com a representatividade numérica e sim com a apreensão do fenômeno em sua essência (Martins \& Bicudo, 1994).

A escolha dos profissionais específicos que participaram se deu de forma aleatória. A técnica escolhida para a captação dos discursos dessa pesquisa foi a entrevista fenomenológica, que permite, como explica Carvalho (1987), o acesso ao rico mundo da experiência vivida pelo outro, na medida em que esse comunica sua singularidade e seu modo de ser tanto através das suas falas quanto por pausas, timbres, tons, ritmos, reticências e expressões não verbais. "[...] A entrevista fenomenológica é uma maneira acessível ao cliente de penetrar a verdade mesma de seu existir, seja ela qual for, sem qualquer falseamento ou deslize, sem qualquer preconceito ou impostura" (p.35).

Essa escolha se deveu à sua natureza interativa, que permite uma troca entre entrevistador e entrevistado, buscando o estabelecimento de uma atitude relacional e dialógica (Oliveira, 2002). Utilizou-se a entrevista fenomenológica, semi-estruturada, mediada pela seguinte pergunta norteadora: Como você se sente trabalhando como profissional de saúde em uma unidade neonatal de alto e médio risco?

Brito (2002) destaca a importância da pergunta norteadora na pesquisa em fenomenologia, uma vez que ela dá início ao diálogo e permite sua continuidade conforme as respostas dos entrevistados, propiciando liberdade tanto para a descrição do entrevistado quanto para novas formulações suscitadas pelo entrevistador no transcorrer da conversa.

Foram realizadas quatro entrevistas, uma para cada categoria profissional apontada anteriormente, 
sem haver um planejamento prévio quanto ao número de entrevistas que seriam realizadas, conforme exposto. A decisão de encerrar a coleta das infor-mações foi tomada quando se percebeu o fenômeno como apreendido. Para Heidegger (2002) não há ponto de chegada na compreensão de um fenômeno, pois a compreensão é sempre apreensível, jamais apreendida. Entretanto, para fins práticos, as informações são colhidas até o momento em que se considera que elas já atendem aos propósitos da investigação em questão (Alves-Mazzoti \& Gewandsnajder, 2001).

Os relatos dos sujeitos foram interpretados através da hermenêutica de Heidegger. A hermenêutica foi escolhida em função da riqueza desse método para interpretar e compreender a experiência do mundo da vida. De acordo com Motta (1997, p.66), "a hermenêutica é a ciência que trata da compreensão e da interpretação como um processo epistemológico e ontológico. É um mapa para entender a linguagem, os símbolos das expressões faladas e escritas. Esse método enfatiza as conexões entre o falante e o mundo no qual ele vive".

A análise das entrevistas partiu da visualização dos discursos coletados pelas entrevistas, descrita por Brito (2002) como a etapa de familiarização com os relatos da experiência vivida, sendo seguida pela etapa de identificação dos significados, culminando com a identificação de três unidades de significado que contêm em si as manifestações dos profissionais entrevistados sobre a vivência dos mesmos na unidade considerada: o cuidar de um recém-nascido, o saber e o fazer do profissional e a saúde mental na interface do cuidar. As unidades temáticas foram em seguida submetidas à compreensão e interpretação a partir de conceitos de Martin Heidegger.

\section{Resultados e Discussão}

A compreensão e interpretação do fenômeno ser-profissional-de-saúde em uma unidade neonatal de alto e médio risco, partindo dos discursos dos profissionais sobre suas vivências, revela uma série de nuances que precisam ser analisadas em um movimento constante entre o ôntico e o ontológico, para que se possa alcançar o sentido desse fenômeno.
Ser-profissional-de-saúde em uma unidade neonatal de alto e médio risco implica cuidar de um recém-nascido frágil e indefeso que apresenta um quadro de saúde grave. Esse quadro oscila diariamente entre momentos de melhora e de piora, sendo constante a ameaça da morte iminente. Diante dessa realidade o profissional se depara com sentimentos de insegurança, impotência e angústia diante das possibilidades do porvir, sentimentos esses que acabam por gerar, em alguns profissionais, mecanismos de fuga do modo existencial-ontológico da pre-sença, refugiando-se na cotidianidade.

Nesse sentido, no dia-a-dia do trabalho, muitas vezes, o profissional assume o modo impessoal de ser da pre-sença, em que ele não aparece como figura central, mas é respaldado pelo todo, que dita como ele deve se comportar. Esse modo impessoal, através da public-idade e do falatório diz ao profissional que não se envolva com o paciente e controle seus sentimentos, pois apenas sendo frio e impessoal ele terá competência e preparação para fazer seu trabalho a contento.

O profissional depara-se assim com a possibilidade de fuga através do uso da capa da indiferença e da onipotência, que faz com que ele não entre em contato com seus reais sentimentos, em decorrência do medo da responsabilização pelos insucessos, interpretados como fracassos pessoais. Nesse sentido, a onipotência leva à postura de tudo sei e tudo posso e à procura de outros culpados para o fracasso: demais profissionais, situações que fugiram ao seu controle e/ou falta de equipamentos e materiais. Tal postura prejudica, a um só tempo, tanto a relação entre profissional e paciente quanto a relação entre os próprios profissionais, que passa a ser marcada por uma série de cobranças e exigências. Nessas relações o outro não é considerado como pre-sença pelo profissional.

Entretanto, um olhar mais cuidadoso sobre as manifestações desse profissional aponta para a possibilidade da pre-sença estar fazendo uso do modo impessoal como proteção, a fim de não entrar em contato com os sentimentos já apontados de insegurança, impotência e angústia diante dos acontecimentos difíceis do ser-profissional-de-saúde no contexto considerado. Essa proteção pode estar até 
mesmo a serviço de preservar a saúde mental do profissional, na medida em que ele tenta fugir desses sentimentos e do sofrimento psíquico e emocional que geram.

Um dos momentos apontados como de intensa dificuldade é o de dar a notícia da morte para os familiares do recém-nascido. Essa dificuldade está ligada à interpretação que esse profissional, protegido pelo modo impessoal, dá aos questionamentos feitos pela família. Sentindo-se acusado ou apontado como responsável, o profissional se fecha e entende a família como incompreensiva e ingrata com o trabalho realizado.

Por outro lado, quando o modo impessoal não está em uso, percebe-se claramente as manifestações do modo existencial de ser da pre-sença. Como sercom, o profissional se relaciona com a mãe desse bebê como co-pre-sença e procura se colocar em seu lugar. Essa relação autêntica entre co-pre-senças permite ao profissional sair de seu mundo e ser tocado existencialmente pela situação dessa mãe e passar tanto a temer por, no sentido de temer a morte do bebê pela família, quanto a modificar a sua prática profissional no intuito de proporcionar um cuidado também com essa mãe, falando o que ele mesmo gostaria de ouvir se estivesse em seu lugar. Percebese a ocorrência do encontro, no sentido mais profundo da palavra, o que traduz uma relação humanizada entre profissional e paciente.

Diante dos procedimentos rígidos e padronizados de uma unidade de alto risco, o profissional passa a "substituir" a mãe nos cuidados com o bebê, situação que ele vivencia como pre-ocupação e que o leva a se sentir verdadeiramente mãe daquele bebê, protegendo-o e realizando um cuidado autêntico, uma preocupação com a vida do outro, com o serexistente e suas possibilidades. Nesse papel de mãe, o profissional vivencia novamente a insegurança, a angústia e a impotência.

Dessa forma, percebe-se que ser-profissional-de-saúde no sentido ontológico de ser da pre-sença significa ser profundamente tocado pelas vivências do cuidar, que implica um envolvimento entre profissional e recém-nascido que transcende os limites da unidade e passa a afetar profundamente a vida pessoal e a saúde mental desse profissional, que pensa, sonha e lembra desse bebê que sofre durante vários momentos da sua vida. Significa ainda viver entre o visível e o invisível, esse último no sentido de buscar reflexões e interpretações de suas vivências.

Assim, esse envolvimento com o bebê e sua família, o sentir-se mãe do bebê, os sentimentos de insegurança, impotência, angústia, dentre outros, geram sofrimento psíquico e emocional profundos e afetam a qualidade de vida dos profissionais, repercutindo na saúde mental dos mesmos. Ser-profissional-de-saúde em uma unidade neonatal de alto e médio risco implica também conhecer as possibilidades de adoecer e morrer e sentir uma angústia profunda diante da indeterminação do porvir, uma vez que ele não está a salvo de passar pela mesma dor dessas mães com quem convive. Nesse sentido, diante de tanta insegurança e desproteção, é mais seguro não ter mais filhos ou refugiar-se na religião para acreditar que será protegido pela vontade de Deus.

Ser-profissional-de-saúde em uma unidade onde a morte é uma ameaça constante e real significa se deparar a cada dia com a angústia fundamental do homem: o fato de que ele e todos os que ele ama são seres-para-o-fim. Diante dessa realidade tão nua e crua e de sentimentos tão profundamente existenciais, pode-se perguntar: como fazer para viver nessa realidade? Qual é a forma mais segura ou mais confortável? A análise dos discursos mostrou que existem alguns caminhos. Cada pre-sença parece escolher o seu.

\section{Conclusão}

Este estudo procurou abordar especificamente a vivência dos profissionais de saúde que trabalham em unidades neonatais de alto e médio risco, após a constatação da quase que completa inexistência de pesquisas que pudessem contribuir para a compreensão dessa realidade.

Pôde-se compreender a partir dos resultados encontrados que o sentido de ser-profissional-de-saúde de uma unidade neonatal transita entre o ôntico e o ontológico na medida em que a pre-sença ora se protege no modo impessoal, ora se coloca no modo existencial-ontológico de ser. Essa oscilação passa 
a ser compreensível na medida em que se percebe que ser-profissional-de-saúde em uma unidade neonatal de alto e médio risco significa passar por vivências e lidar com situações que geram um intenso sofrimento psíquico e emocional, interferindo na qualidade de vida desses profissionais e afetando a saúde mental dos mesmos.

Ser-profissional-de-saúde é ser gente, é ser humano, com todas as repercussões que isso significa. Assim, deve-se lembrar que ser-profissional-de-saúde é lidar diariamente com sentimentos e situações que seriam preferíveis de serem esquecidas ou escondidas, mas, existencialmente, ainda não se descobriu como. É querer calar aquilo que constitui os homens como seres pensantes e questionadores, como pre-senças.

Apenas adentrando cada vez mais nesse contexto de compreensão das vivências dos profissionais de saúde é que se poderá realmente favorecer mudanças nas relações entre profissionais e pacientes, visando à humanização do atendimento. Afinal, humanizar não é apenas atender melhor. Para mudar relações, precisamos olhar para os dois lados envolvidos. Que outros interlocutores possam aderir a essa idéia para que se possa contribuir com visões que priorizem as manifestações do ser, por vezes tão esquecido em um mundo de tantas possibilidades.

\section{Referências}

Alves-Mazzoti, A.J., \& Gewandsnajder, F. (2001). O método nas ciências naturais e sociais: pesquisa quantitativa e qualitativa. São Paulo: Pioneira.

Barguil, P.M., \& Leite, R.C.M. (1997). Voltemos às próprias coisas: o convite da fenomenologia. In J.A.E. Barreto \& R.V.O. Moreira. Imaginando erros (Escritos de filosofia da ciência) (pp.79-111). Fortaleza: Casa de José de Alencar, (Coleção Alagadiço Novo).

Brito, M.H.A. (2002). Ser-mãe-de-prematuro: o cuidado inimitável da presença materna. Dissertação de mestrado, Centro de Ciências da Saúde, Universidade Estadual do Ceará, Fortaleza.

Carvalho, A.S. (1987). Metodologia da entrevista: uma abordagem fenomenológica. Rio de Janeiro: Agir.
Forghieri, Y.C. (2001). Psicologia fenomenológica: fundamentos, método e pesquisa. São Paulo: Pioneira Thomson.

Heidegger, M. (2002). Ser etempo (Parte 1). Petrópolis: Vozes. Heidegger, M. (2002). Ser etempo (Parte 2). Petrópolis: Vozes.

Lamy, Z.C. (1995). Estudo das situações vivenciadas por pais de recém-nascidos internados em unidade de terapia intensiva neonatal. Dissertação de mestrado, Instituto Fernandes Figueira, Fundação Oswaldo Cruz, Rio de Janeiro.

Martins, J., Bicudo, M.A.V. (1994). Pesquisa qualitativa em psicologia: fundamentos e recursos básicos. São Paulo: Editora Moraes.

Moreira, D.A. (2002). O método fenomenológico na pesquisa. São Paulo: Pioneira Thomson.

Moreira, R.V.O., Barreto, T.A.E., Machado, R.C.C., \& Andrade, T.P.P. (1999). A reconstrução da metafísica através do método fenomenológico. In J.A.E. Barreto \& R.V.O. Moreira (Orgs.). O elefante e os cegos. Fortaleza: Casa de José de Alencar.

Moreno, R.L.R. (2002). Revelação de experiências maternais em unidade de terapia intensiva: visão fenomenológica. Dissertação de mestrado, Centro de Ciências da Saúde, Universidade Estadual do Ceará, Fortaleza.

Morsch, D.S. (1990). O desenvolvimento afetivo em situação de alto risco neonatal: um estudo sobre o processo de interação. Dissertação de mestrado, Departamento de Psicologia, Pontifícia Universidade Católica do Rio de Janeiro.

Motta, M.G.C. (1997). Oser doente no tríplice mundo da criança, familia e hospital: uma descrição fenomenológica das mudanças existenciais. Tese de doutorado, Centro de Ciências da Saúde, Universidade Federal de Santa Catarina, Florianópolis.

Oliveira, V.L.M. (2002). A construção do conhecimento: do saber ao saber-fazer. Fortaleza: Edições do Autor.

Ribeiro, L.M.S.A. (1991). Prematuro, quem é esse bebê? As singularidades de bebês que nascem pré-termo em questão. Dissertação de mestrado, Instituto Fernandes Figueira, Fundação Oswaldo Cruz, Rio de Janeiro.

Silva, L.F., Gurgel, A.H., Carvalho, Z.M.F., \& Moreira, R.V.O. (2001). Cuidado como essência humana em Martin Heideggere a enfermagem. In: J.A. Barreto \& R.V.O. Moreira. (Orgs.). A outra margem: filosofia, teorias de enfermageme cuidado humano. Fortaleza: Casa de José de Alencar.

Spanoudis, S. (1981). Apresentação: a todos que procuram o próprio caminho. In M. Heidegger. Todos nós... ninguém: um enfoque fenomenológico do social. São Paulo: Moraes.

Recebido para publicação em 16 de março de 2004 e aceito em 28 de março de 2005. 